\title{
Association Between Polymorphisms of CTLA-4 + 49A > G Locus and Susceptibility of Upper Gastrointestinal Cancer: A Systematic Review and Meta-Analysis
}

\author{
Xu Zhang \\ Lanzhou University Second Hospital \\ Xiao-dong He ( 15293155132@139.com ) \\ You-cheng Zhang \\ Lanzhou University Second Hospital \\ Ke-hu Yang \\ Lanzhou University \\ Jin-hui Tian \\ Lanzhou University \\ Yao-long Chen \\ Lanzhou University
}

Lanzhou University Second Hospital https://orcid.org/0000-0001-6319-7013

\section{Research Article}

Keywords: upper gastrointestinal tumor, CTLA-4, esophageal cancer, gastric cancer, gene polymorphism, case-control study

Posted Date: May 21st, 2021

DOI: https://doi.org/10.21203/rs.3.rs-481800/v1

License: () (1) This work is licensed under a Creative Commons Attribution 4.0 International License. Read Full License 


\section{Abstract}

Objective: To explore the correlation between CTLA-4 + 49A > G polymorphism and risks of upper gastrointestinal cancer.

Methods: Searched Pubmed, Embase, Cochran Library, Chinese Biomedical Literature Database, Chinese CNKI, VIP and Wanfang database, retrieve the deadline to Feb 2021. Document acquired independently by the two collectors according to inclusion and exclusion criteria. System analysis was performed by Revman 5.3 software.

Results: A total of seven case-control studies were included in the study, including 3045 patients and 3545 controls. The results of the systematic analysis showed that all studies on upper gastrointestinal tumors were combined: random effects model, dominant genetic model GG + GA vs AA: the difference was not statistically significant [OR=1.15; 95\%Cl: 0.74-1.81]; recessive genetic model GG vs GA + AA [OR=0.99; 95\%Cl: 0.74-1.31], codominant model GG vs AA [OR=1.14; $95 \% \mathrm{Cl}: 0.67-1.95]$, GA vs AA [OR=1.20; $95 \% \mathrm{Cl}$ : $0.80-1.79]$, allele model $\mathrm{G}$ vs $\mathrm{A}$ [OR=1.06; $95 \% \mathrm{Cl}$ : 0.82-1.38]. The above results show $\mathrm{CTLA}-4+49 \mathrm{~A}>\mathrm{G}$ locus. There was no correlation between gene polymorphism and susceptibility to upper gastrointestinal tumors including gastric cancer and esophageal cancer. After the five studies on gastric cancer were combined, each genetic model showed that the CTLA-4 + 49.

Conclusion: This study showed that there was no correlation between single nucleotide polymorphisms in CTLA-4 + 49A > G locus and upper gastrointestinal tumors including gastric cancer and esophageal cancer.

\section{Introduction}

Gastrointestinal tumor is a common human disease, which seriously endangers people's health ${ }^{[1]}$. Stomach cancer is the 4th most common cancer in the world ${ }^{[2]}$, esophageal cancer is the 3rd common cause of cancer death. With the development of society, its incidence rate is also rising and increasing year by year ${ }^{[3-5]}$.

Cytotoxic T lymphocyte antigen 4 (CTLA-4) is an important inhibitory regulator of T cell proliferation and activation ${ }^{[6]}$, it induces Fas-independent apoptosis of activated T cells. The cytotoxic T lymphocyte-associated antigen 4 gene is located on chromosome $2 q 33$, and its expression product is the leukocyte surface antigen CD152, which competes with CD28 for binding ligand B7-1/B7-2, thereby negatively regulating cell proliferation and activation and decreasing the occurrence of anti-tumor immune responses in humans, thus increasing tumor susceptibility ${ }^{[7]}$. It has been found that CTLA-4 single nucleotide polymorphisms (SNPs) can affect the expression of CTLA-4 gene from different expression links and are closely associated with genetic susceptibility to tumors such as gastric and breast cancers ${ }^{[8]}$. Zheng ${ }^{[9]}$ suggested that CTLA-4 $+49 \mathrm{G} / \mathrm{A}$ polymorphism was associated with the development of solid tumors (including colorectal, gastric, esophageal, skin, thymoma, nasopharyngeal, and cervical squamous carcinomas). Zhang ${ }^{[10]}$ showed that the polymorphisms were not associated with gastric and colorectal cancers. Liu ${ }^{[11]}$ also reported no statistically significant association between CTLA-4 $+49 \mathrm{G} / \mathrm{A}$ polymorphisms and the risk of digestive system cancers. In this study, the collected studies were systematically analyzed by including case-control studies on the association between upper $\mathrm{GI}$ tract tumor susceptibility risk and CTLA- $4+49$ gene polymorphism, and then understanding the association between the mechanistic process of upper GI tract tumorigenesis and single nucleotide polymorphisms at the CTLA-4 + 49A > G locus

\section{Materials And Methods}

Literature Retrieval Strategy

Search Pubmed, Cochran Library, Embase, China Biomedical Network, China Knowledge Network, Wanfang and Wipu databases, search the period from library constructioned to Feb 2021, with "CTLA-4", "Single Nucleotide Polymorphism" or "single nucleotide polymorphism", "gastriccancer oresophagealcancer or upper gastrointestinal cancer" or "stomach cancer, esophageal cancer, or upper gastrointestinal tract tumor" as search terms. At the same time, carried out necessary manual retrieval as a supplement.

Inclusion and Exclusion Criteria

Inclusion criteria: (1) Studies of upper gastrointestinal tract tumors including esophageal and gastric cancers with susceptibility to single nucleotide polymorphisms at the CTLA-4 + 49A > G locus; (2) Case controlled study; (3) Data in the text must be complete. 
Exclusion criteria: (1) No control group studies, for reviews, reports and other similar literature; (2) Duplicates or literature with incomplete information; (3) Studies with precancerous lesions such as esophagitis and atrophic gastritis as control groups.

Literature Quality Evaluation Criteria

Applying the Newcastle-Ottawa scale, NOS ${ }^{[12]}$ criteria, all literature was evaluated for relevance by analyzing 3 aspects of casecontrol selection, comparability, and exposure information, and literature extraction was performed independently by $\geq 2$ study participants. When the control genotype distribution deviated from HWE, studies with control genotype distribution deviating from HWE were included first, and then sensitivity analyses were performed to compare the stability of the results or to test whether there were differences between groups ${ }^{[13-16]}$.

\section{Statistical Analysis}

The RevMan 5.3 software was used to perform the analysis of effect sizes, and in the heterogeneity test, the $\mathrm{I}^{2}$ test was applied to the included studies, and when there was heterogeneity among the studies, $P<0.1$ or $I^{2}>50 \%$, the effect sizes were combined by means of a random-effects model, and when the results were reversed, a fixed-effects model was adopted. Processing of sensitivity analysis: meta-analysis was performed after excluding one literature at a time. Egger and Begg tests made with Stata 12.0 software were used to determine whether there was publication bias.

\section{Results}

Basic Characteristics of the Included Literature

A total of 75 relevant papers were retrieved for this study. After de-duplication, reading the titles and abstracts, 40 duplicate and irrelevant literatures were excluded. After reading the full text, 8 papers were finally included, and the basic characteristics of the included papers are shown in Table 1, including 3 case-control studies of esophageal cancer ${ }^{[17-19]}$ and 5 case-control studies of gastric cancer ${ }^{[18,20-23]}$; one ${ }^{[18]}$ of the eight papers simultaneously analyzed the correlation between the risk of esophageal cancer, gastric cancer and CTLA-4 + 49A > G gene polymorphism. 
Table 1

Basic Characteristics of the Included Literature

\begin{tabular}{|c|c|c|c|c|c|c|c|c|c|c|c|c|c|}
\hline \multirow[t]{2}{*}{ Study } & \multirow[t]{2}{*}{ Time } & \multirow[t]{2}{*}{ Country } & \multirow{2}{*}{$\begin{array}{l}\text { Tumor } \\
\text { type }\end{array}$} & \multirow{2}{*}{$\begin{array}{l}\text { Control } \\
\text { group } \\
\text { source }\end{array}$} & \multirow{2}{*}{$\begin{array}{l}\text { Staging } \\
\text { method }\end{array}$} & \multicolumn{3}{|c|}{ Case group } & \multicolumn{3}{|c|}{ Control group } & \multirow{2}{*}{$\begin{array}{l}\text { Control } \\
\text { group } \\
\text { HEW/P- } \\
\text { value }\end{array}$} & \multirow{2}{*}{$\begin{array}{l}\text { NOS } \\
\text { scale }\end{array}$} \\
\hline & & & & & & GG & GA & AA & GG & GA & $A A$ & & \\
\hline $\operatorname{Liu}^{[17]}$ & 2015 & China & ESCC & hospital & $\begin{array}{l}\text { PCR- } \\
\text { RFLP }\end{array}$ & 307 & 254 & 43 & 310 & 296 & 58 & 0.28 & 8 \\
\hline $\operatorname{Sun}^{[18]}$ & 2008 & China & ESCC & hospital & RFLP & 448 & 434 & 128 & 529 & 406 & 73 & 0.68 & 8 \\
\hline Cheng $^{[19]}$ & 2011 & China & ESCC & hospital & $\begin{array}{l}\text { PCR- } \\
\text { RFLP }\end{array}$ & 54 & 105 & 46 & 90 & 79 & 36 & 0.01 & 7 \\
\hline Hadinia $^{[20]}$ & 2007 & Iran & GC & hospital & $\begin{array}{l}\text { PCR- } \\
\text { RFLP }\end{array}$ & 6 & 13 & 24 & 14 & 59 & 117 & 0.09 & 8 \\
\hline $\begin{array}{l}\text { Yu-qin } \\
Y^{[21]}\end{array}$ & 2012 & China & GC & hospital & $\begin{array}{l}\text { PCR- } \\
\text { RFLP }\end{array}$ & 65 & 45 & 8 & 30 & 45 & 21 & 0.59 & 8 \\
\hline $\mathrm{Hou}^{[22]}$ & 2010 & China & GC & hospital & $\begin{array}{l}\text { PCR- } \\
\text { ARMS }\end{array}$ & 94 & 70 & 41 & 107 & 55 & 100 & $\llbracket 0.05$ & 7 \\
\hline $\operatorname{Sun}^{[18]}$ & 2008 & China & GC & Hospital & $\begin{array}{l}\text { PCR- } \\
\text { RFLP }\end{array}$ & 235 & 235 & 60 & 282 & 209 & 39 & 0.97 & 8 \\
\hline Tang $^{[23]}$ & 2016 & China & GC & hospital & $\begin{array}{l}\text { PCR- } \\
\text { RFLP }\end{array}$ & 155 & 153 & 22 & 278 & 264 & 48 & 0.179 & 7 \\
\hline
\end{tabular}

Meta-Analysis of CTLA-4 + 49A > G Single Nucleotide Polymorphisms and Susceptibility to Upper Gastrointestinal Tract Tumors

In the dominant genetic model: GG + GA: AA, the differences in heterogeneity tests between studies were statistically significant, and using a random-effects model, the combined results showed that the correlation between upper gastrointestinal tumor susceptibility and CTLA-4 + 49 locus polymorphism was not statistically significant (OR $=1.15,95 \% \mathrm{C} 1: 0.74-1.81$, see Fig. 1.). The funnel plots were basically symmetrical (see Fig. 2.), and the results of Begg's test had a P value of 0.216 and Egger's test had a $P$ value of 0.111 , showing no significant publication bias. The combined effect size of each genetic model did not change significantly after sequentially excluding 1 literature individually, suggesting that the correlation between the risk of upper gastrointestinal tumor development and CTLA-4 + 49 locus polymorphism was not statistically significant and the combined results were stable.

In the recessive genetic model GG: GA + AA, the co-dominant model GG: $A A, G A: A A$, and the allelic genetic model G: $A$, the differences in heterogeneity tests between studies were statistically significant, all using the random effects model, and the combined results were: recessive genetic model GG: $G A+A A(O R=0.99,95 \% \mathrm{Cl}: 0.74-1.31)$, see Fig. 3. Co-dominant model GG: $A A$ $(\mathrm{OR}=1.14,95 \% \mathrm{Cl}: 0.67-1.95)$, see Fig. 4. GA:AA $(\mathrm{OR}=1.20,95 \% \mathrm{Cl}: 0.80-1.79)$, see Fig. 5. Allelic model G: $\mathrm{A}(\mathrm{OR}=1.06,95 \% \mathrm{Cl}$ : 0.82-1.38), indicating that the development of upper gastrointestinal tumors was not correlated with CTLA-4 + 49 gene polymorphism was not correlated. In the allelic model G:A, the P value of the result of Begg's test was 0.216 and the $P$ value of the result of Egger's test was 0.114 (see Fig. 6.). The combined effect size of each genetic model did not change significantly when 1 literature was excluded individually in turn. When 2 literatures ${ }^{[19,22]}$ that did not conform to $\mathrm{H}-\mathrm{W}$ equilibrium were excluded, the combined results GG: GA + AA (OR = 1.07, 95\% Cl: 0.78-1.43), GG: AA (OR=1.18, 95\% Cl: 0.64-2.18), GA: AA (OR = 1.00, 95\% Cl: $0.70-1.44)$, and $\mathrm{G}: \mathrm{A}(\mathrm{OR}=1.08,95 \% \mathrm{Cl}: 0.82-1.42)$, suggesting that the correlation between the risk of upper gastrointestinal tumor development and the polymorphism of the CTLA-4 + 49 locus was not statistically significant.

Association of the CTLA-4 + 49 Locus with Susceptibility to Gastric Cancer 
In the dominant genetic model: GG + GA: AA, the recessive genetic model GG: GA + AA, the co-dominant models GG: $A A$, GA: $A A$, and the allelic genetic model $\mathrm{G}: \mathrm{A}$, the differences in the test of heterogeneity between studies were statistically significant, and using the random effects model, the combined results were: dominant genetic model ( $O R=1.50,95 \% \mathrm{Cl}$ : 0.80-2.81), see Fig. 7 . Recessive genetic model GG: GA + AA (OR $=1.23,95 \% \mathrm{Cl}: 0.81-1.88)$, see Fig. 8. Co-dominant models GG: $\mathrm{AA}(\mathrm{OR}=1.65,95 \% \mathrm{Cl}$ : 0.78-3.50), GA: AA (OR = 1.48, 95\% Cl: 0.82-2.69), allelic genetic model G: A (OR = 1.29, 95\% Cl: 0.87-1.91), showed no correlation between the development of gastric cancer and CTLA-4 + 49 gene polymorphism, and the Begg and Egger tests in each genetic model also showed no significant publication bias, and the reliability of the conclusions was good.

\section{Discussion}

Gastrointestinal tumors are one of the major diseases that endanger human health, and their treatment and prevention are urgent issues to be addressed.

Nistico ${ }^{[24]}$ reported an A-G dimorphism at position 49 of CTLA-4 exon 1 (rs231775), a polymorphism that causes amino acid exchange of threonine with alanine in the leading sequence of this protein. It was found that this polymorphism may also affect the ability of CTLA-4 to bind to B7-1/B7-2, which may affect T-cell activation ${ }^{[25]}$. The results suggest that the $\mathrm{G}$ allele at position + 49 but not the A allele attenuates the CTLA-4-driven downregulation of T-cell response ${ }^{[24]}$. However, there are conflicting findings regarding the association between the $+49 \mathrm{~A}>\mathrm{G}$ polymorphism and cancer risk. Therefore, the authors performed meta-analysis and systematic review of all eligible case-control studies to summarize and analyze data from published studies so as to assess the association between CTLA-4 + 49A-G polymorphism and risk of gastric and esophageal cancers

In this study, the combined results across genetic models showed that there was no correlation between gene polymorphisms at the CTLA-4 + 49A > G locus and susceptibility to upper gastrointestinal tract tumors, including gastric and esophageal cancers. A subgroup analysis of studies on gastric cancer was performed, and there was also no significant correlation between the CTLA-4 + $49 \mathrm{~A}>\mathrm{G}$ locus gene polymorphism and gastric cancer in each genetic model. When the 2 papers ${ }^{[19,22]}$ that did not fit the $\mathrm{H}-\mathrm{w}$ balance were excluded and combined again and compared with the total combined results, the results showed agreement with the total combined results and better stability of the pooled results.

Zheng ${ }^{[9]}$ conducted a meta-analysis with only three studies on gastric cancer and only one on esophageal cancer and reported that CTLA-4 + 49A/G polymorphism was associated with the occurrence of solid tumors (including colorectal cancer, gastric cancer, esophageal cancer, etc.). Liu ${ }^{[11]}$ conducted a meta-analysis with four studies on gastric cancer and only two on esophageal cancer and reported no statistically significant risk between CTLA-4 + 49 G/A polymorphism and digestive system cancers, and no significant association between CTLA-4 + 49 G/A polymorphism and gastric cancer was observed in the subgroup analysis. In this study, comparison of the results of the sensitivity analysis with the overall combined results showed that the pooled results may be more stable than the results of the above analysis.

This study has the limitation that the included literature is ethnically Asian, so a large number of well-designed epidemiological studies are still needed to validate the findings.

\section{Conclusion}

This study showed that there was no correlation between single nucleotide polymorphisms in CTLA-4 + 49A > G locus and upper gastrointestinal tumors including gastric cancer and esophageal cancer.

\section{Declarations}

Acknowledgements: We are grateful to Mr. He Xiaodong and Mr. Zhang Youcheng of the Second Hospital of Lanzhou University for their support in data management, and to Mr. Yang Kehu, Mr. Tian Jinhui and Mr. Chen Yaolong of the Evidence-based Centre of the School of Basic Medicine of Lanzhou University for their support in statistical data.

Author Contributions: All authors made substantial contributions to conception and design, acquisition of data, or analysis and interpretation of data; took part in drafting the article or revising it critically for important intellectual content; gave final approval of 
the version to be published; and agree to be accountable for all aspects of the work.

\section{Compliance with ethical standards}

Conflict of interest: The authors declare that they have no conflict of interest. The present study was conducted following the Helsinki Declaration of the World Medical Association. All participants have given consent for publication.

Funding: This research received no specific funding/grant from any funding agency in the public, commercial, or not-for-profit sectors.

Ethics approval and consent: Not applicable.

Consent for publication: Not applicable.

An availability of data and materials: All data generated or analysed during this study are included in this published article.

\section{References}

1. BOS ACRK, MATTHIJSEN R A, van ERNING F N, et al. Treatment and out come of synchronous colorectal carcinomas: A nationwide study[J]. Ann Surg Oncol. 2018;25:414-21.

2. JEMAL A, BRAY F, CENTER M M, et al. Global cancer statistics[J]. CA Cancer J Clin. 2011;61:69-90.

3. Tong-sheng M, Juan Z. Effect of laparoscopic and open surgery on the nutritional status of patients with gastrointestinal neoplasms [J]. Clinical Research Practice. 2017;2(36):88-9.

4. Fei-liang Y, Yi D, Xiang L. Effects of laparoscopic surgery and traditional laparotomy on prothrombin and efficacy in patients with gastrointestinal tumor [J]. Contemporary Medicine. 2018;24(3):57-9.

5. Jian-lin Z, Bai-sheng X. Laparoscopic-assisted Gastrointestinal Tumor Surgery: A Report of 43 Cases [J]. Jiangxi Pharmaceutical. 2017;52(9):866-7.

6. PEGGS K S, QUEZADA S A, ALLISON JP. Cell intrinsie mechanisms of T-cell inhibition and application to cancer therapy [J]. Immunol Rev. 2008;224:141-65.

7. DE PALMA M. The role of the immune system in cancer: from mechanisms to clinical applications [J]. Biochim Biophys Acta. 2016;1865:1-2.

8. LI D, ZHANG Q, XU F, et al. Association of CTLA-4 gene polymorphisms with sporadic breast cancer risk and clinical features in Han women of northeast China [J]. Mol Cell Biochem. 2012;364:283-90.

9. ZHENG J, Yu X, JIANG L, et al. Association between the Cytotoxic T-lymphocyte antigen $4+49 \mathrm{G}>$ A polymorphismand cancer risk: a meta-analysis [J]. BMC Cancer. 2010;10:522.

10. ZHANG Y, ZHANG J, DENG Y, et al. Polymorphisms in the eytotoxic T-lymphocyte antigen 4 gene and cancer risk: a metaanalysis [J]. Cancer. 2011;117:4312-24.

11. BAOHONG XIAOLEIL, HAIPENG Y. R, et al. Current evidence on the cytotoxie T-lymphocyte antigen $4+49 \mathrm{G}>\mathrm{A}$ polymorphism and digestive system cancer risks: a meta-analysis involving 11,923 subjects [J].Meta Gene, 2015, 6: 105-108.

12. Xian-tao Z, Hui L, Xi C, et al. Meta-analysis Series IV: Quality assessment tools for observational studies [J]. Chinese Journal of Evidence-Based Cardiovascular Medicine. 2012;4(4):297-9.

13. DOEBLER P, HOLLING H, et al. A mixed model approach to meta-analysis.

14. of diagnostic studies with binary testouteome [J]. Psychol Methods. 2012;17:418-36.

15. NAKAOKA H, INOUE I. Meta-analysis of genetic association studies: methodologies, between-study heterogeneity and winner's curse [J]. J Hum Genet. 2009;54:615-23.

16. SAGOO GS, LITTLE J, HIGGINS JP. Systematic reviews of genetic association studies. Human genome epidemiology network [J]. PLoS Med. 2009;6:e28.

17. MINELLI C, THOMPSON J R, ABRAMS K R, et al. How should we use information about HWE in the meta-analyses of genetic association studies? [J]. Int J Epidemiol. 2008;37:136-46.

Page 6/10 
18. LIU C, WANG Y, JIANG H, et al. Association between Cytotoxic T-lymphocyte antigen 4 (CTLA-4) + 49G > A (rs231775) polymorphism and esophageal cancer: from a case-control study to a meta-analysis [J]. Int J Clin Exp Med. 2015;8:17664-73.

19. SUN T, ZHOU Y, YANG M, et al. Functional genetic variations incytotoxic T-lymphocyte antigen 4 and susceptibility to multiple types of cancer [J]. Cancer Res.

20. 2008., 68: 7025-7034.

21. CHENG X L, NING T, XU C Q, et al. Haplotype analysis of CTLA 4 gene and risk of esophageal squamous cell carcinoma in Anyang area of China [J]. Hepatogastroenterology. 2011;58:432-7.

22. HADINIA A, HOSSIENI S V, ERFANI N, et al. CTLA-4 gene promoter and exon 1 polymorphisms in Iranian patients with gastric and colorectal cancers [J]. J Gastroenterol Hepatol. 2007;22:2283-7.

23. Yu-qin Y, Wei-li C, Jun-li S, et al.The association of CTLA-4 gene promoter and exon region polymorphism with gastric cancer [C] / The 10th Digestive Disease Conference of Shandong and the 7th Gastroscopy Conference, 2012.

24. HOU R, CAO B, CHEN Z, et al. Association of cytotoxic Tlymphocyte-associated antigen-4 gene haplotype with the susceptibility to gastric cancer [J]. Mol Biol Rep. 2010;37:515-20.

25. TANG W, WANG Y, CHEN S, et al. Investigation of cytotoxic T-lymphocyte antigen 4 polymorphisms in gastric cardia adenoeareinoma [J]. Scand J Immunol. 2016;83:212-8.

26. NISTICO L, BUZZETTI R, PRITCHARD L E, et al. The CTLA-4 gene region of chromosome 2 q33 is linked to, and associated with, type 1 diabetes. Belgian Diabetes Registry [J] Hum Mol Genet. 1996;5:1075-80.

27. SUN T, ZHOU Y, YANG M, et al. Functional genetic variations in cytotoxic T-lymphocyte antigen 4 and susceptibility to multiple types of cancer [J]. Cancer Res. 2008;68:7025-34.

\section{Figures}

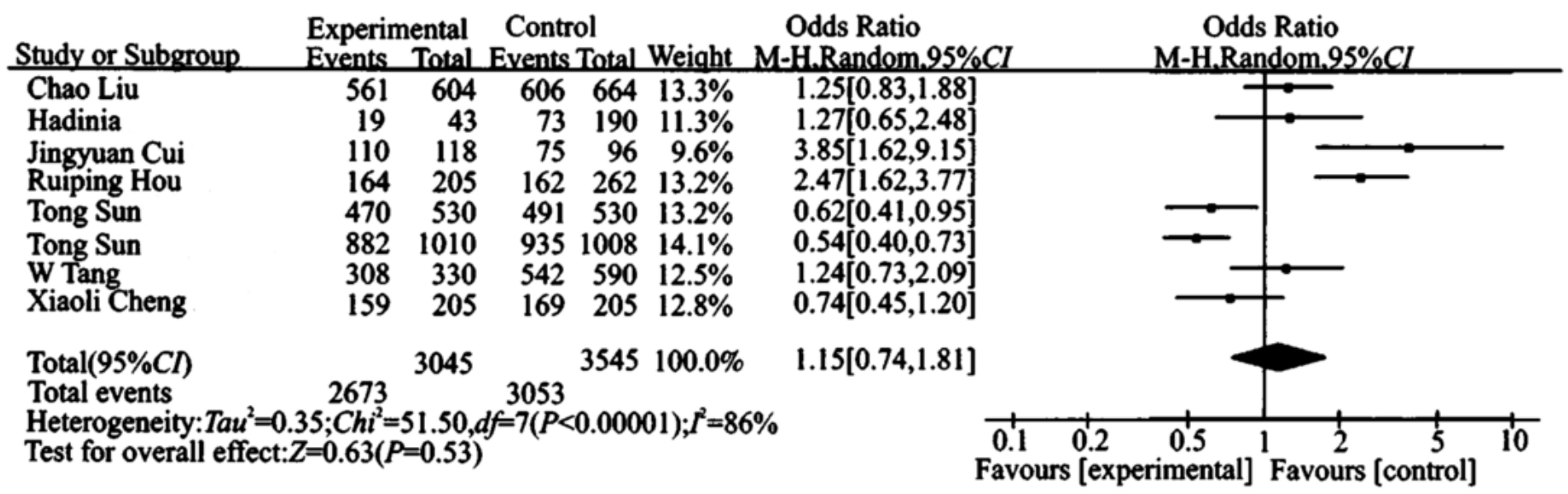

Figure 1

Forest plot of association between CTLA-4 + 49 locus and susceptibility to upper gastrointestinal tract tumors (GG + GA: AA model) 


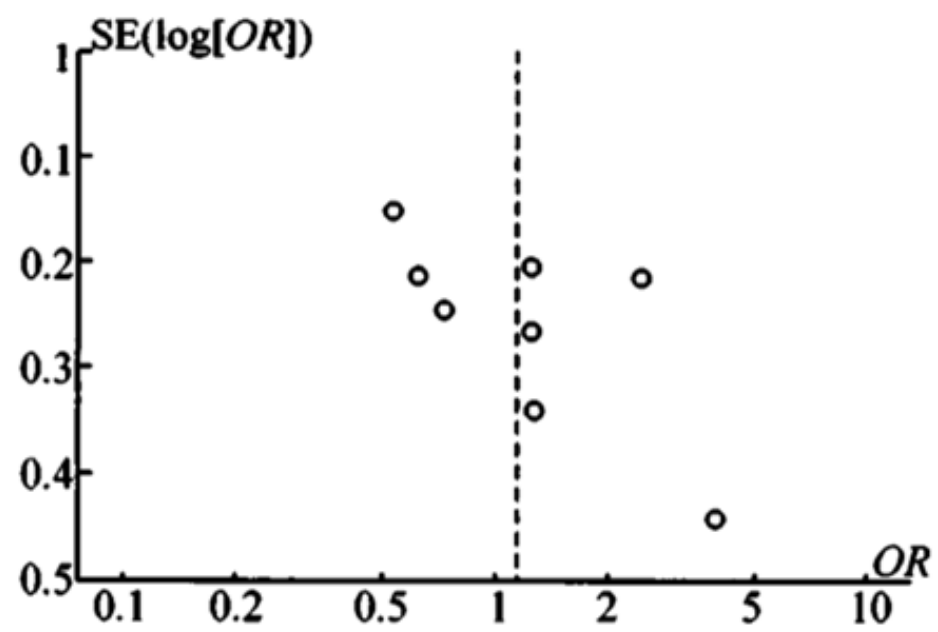

Figure 2

Association funnel plot of CTLA-4 + 49 locus with susceptibility to upper gastrointestinal tract tumors (GG + GA: AA model)

\begin{tabular}{lrrrrrrrr} 
& \multicolumn{1}{c}{$\begin{array}{c}\text { Experimental } \\
\text { Study or Subgroup }\end{array}$} & $\begin{array}{c}\text { Control } \\
\text { Events }\end{array}$ Total & Events Total & Weiqht & M-H.Random.95\%Cl & Odds Ratio \\
Ch-H.Random.95\%CI
\end{tabular}

Figure 3

Forest plot of association between CTLA-4 + 49 locus and susceptibility to upper gastrointestinal tract tumors (GG: GA + AA model)

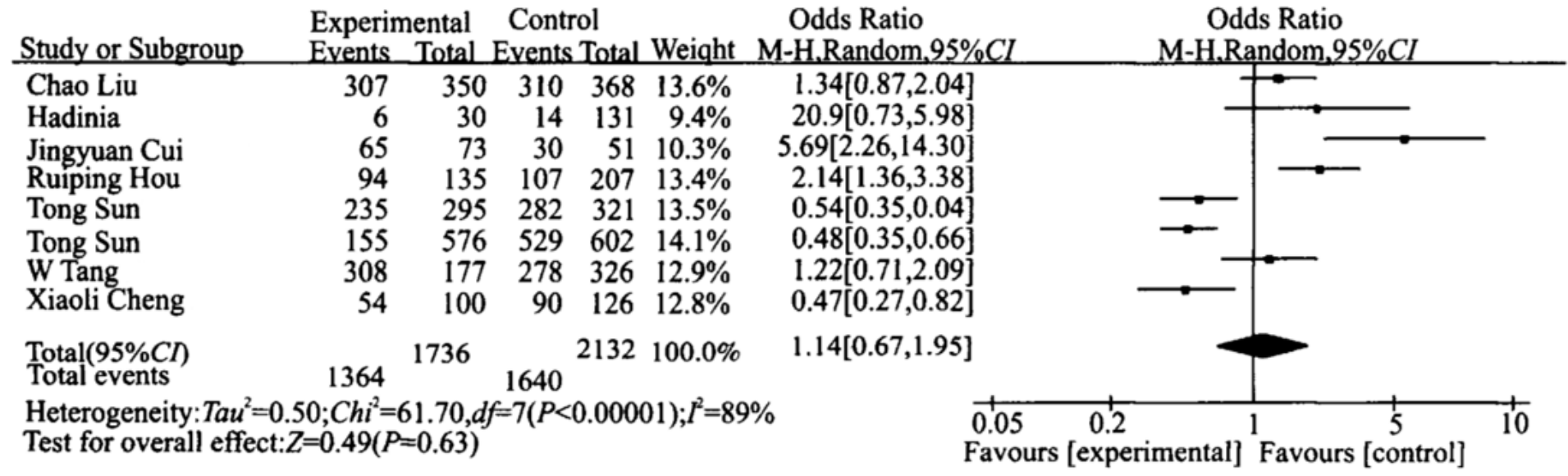

Figure 4

Forest plot of association between CTLA-4 + 49 locus and susceptibility to upper gastrointestinal tract tumors (GG: AA model) 


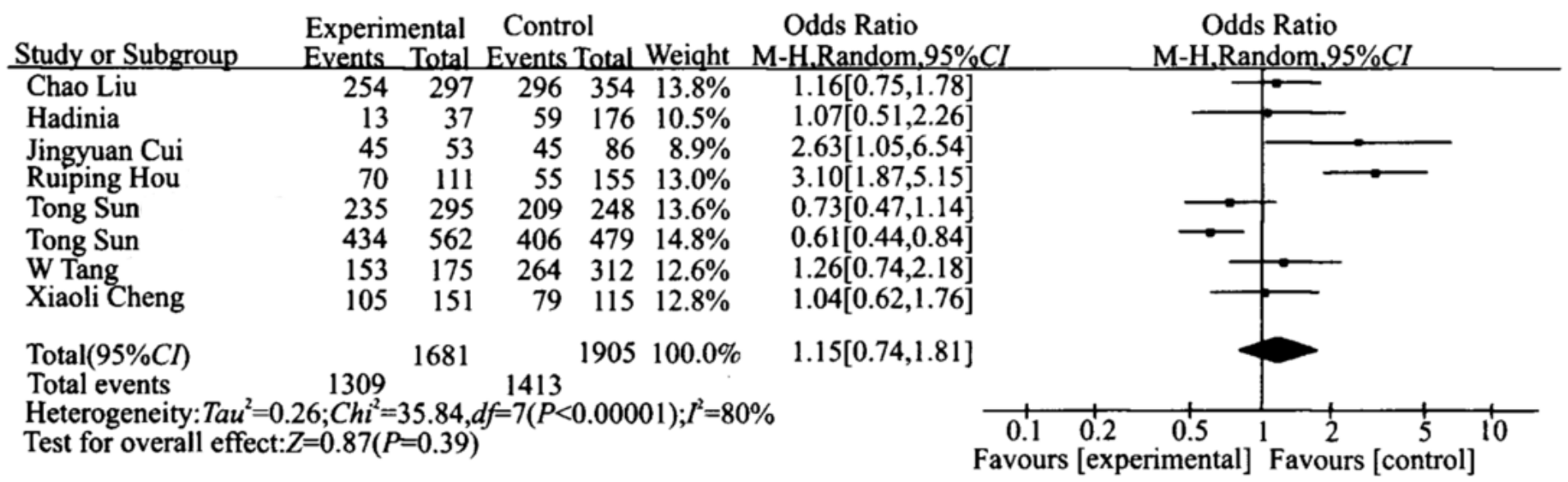

Figure 5

Forest plot of association between CTLA-4 + 49 locus and upper gastrointestinal tumor susceptibility (GA: AA model)

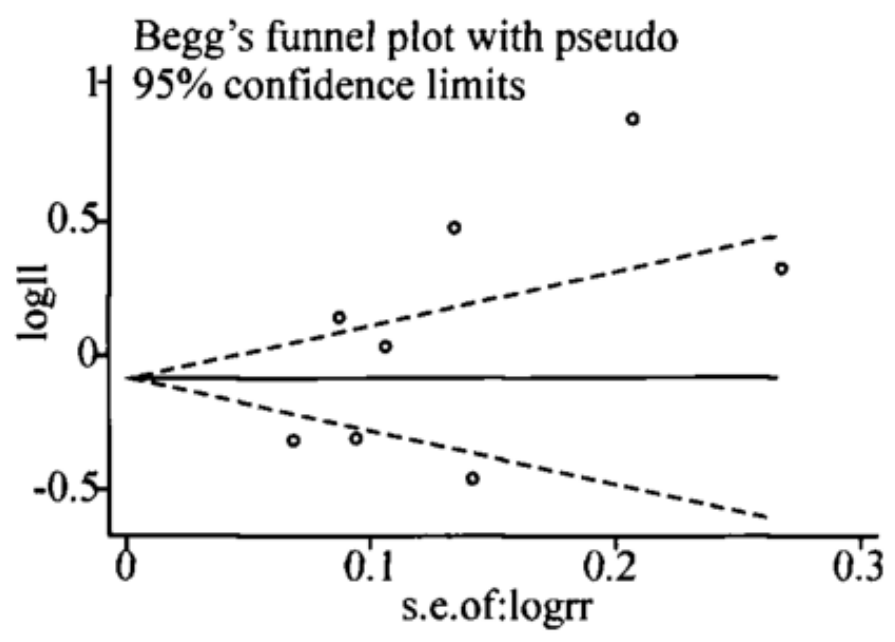

Figure 6

CTLA-4 + 49 locus and upper gastrointestinal tumor susceptibility begg plot (G: A model)

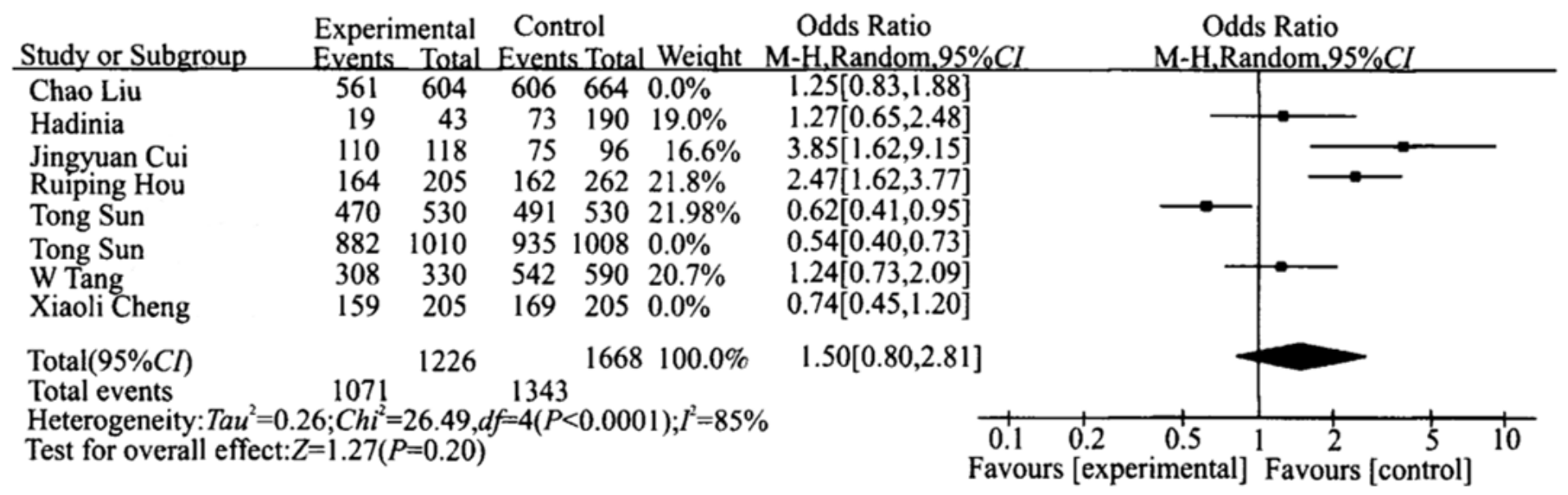

Figure 7

Forest plot of association between CTLA-4 +49 locus and susceptibility to gastric cancer (GG + GA: AA model) 


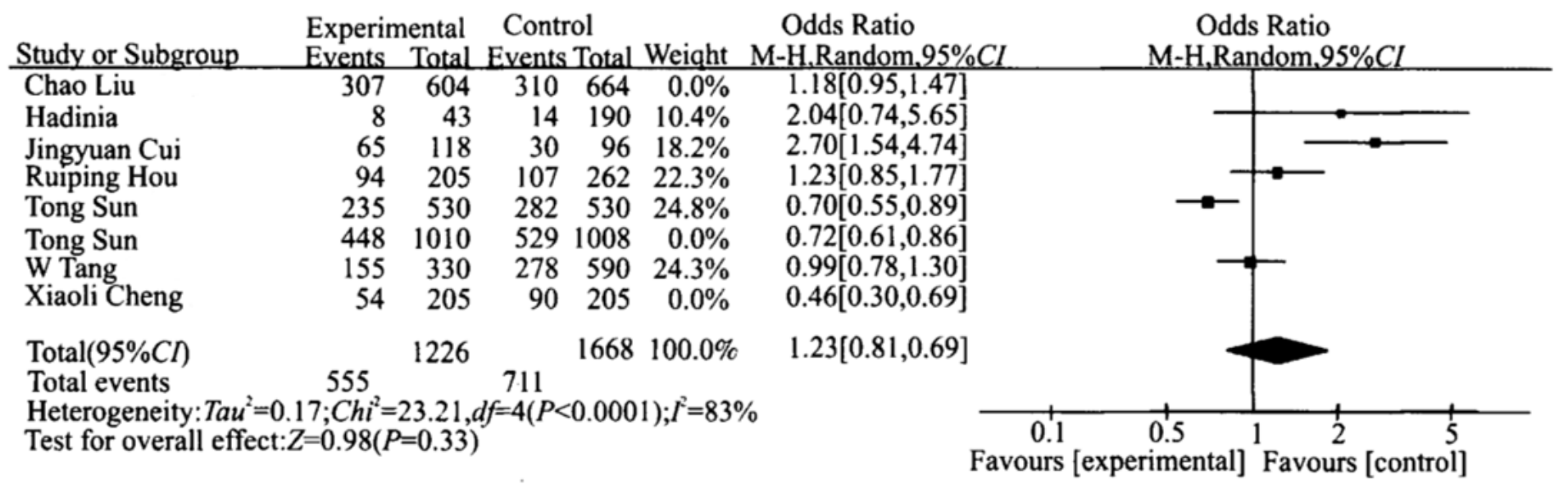

Figure 8

Forest plot of association between CTLA- $4+49$ locus and susceptibility to gastric cancer (GG: GA + AA model) 